\title{
Competing Against an In-House Supplier
}

\author{
John W. Henke, Jr. \\ A. Richard Krachenberg \\ Thomas F. Lyons
}

A not uncommon situation in industrial marketing is for an outside supplier to find itself competing against an in-house supplier. Knowing how to compete against an in-house supplier is of importance because industrial marketing firms typically respond with one of two diametrically opposed actions: they act as if the situation is no different than competing against any other supplier, or they assume that they have no chanceand back off. Neither approach is realistic. The fact that the current supplier is in-house will not impact the probability of the outside vendor's success. Rather, it is the nature of the relationship between the buying organization and the in-house supplier that is of paramount importance in determining the likelihood of replacing an in-house supplier. This article presents a decision-process model useful for ascertaining the sales opportunity when competing against an in-house supplier. Alternative marketing strategies are also suggested.

\section{INTRODUCTION}

Of all the activities that an industrial marketing organization must carry out, the evaluation or qualifying

Address correspondence to John W. Henke, Jr., Ph.D., Oakland University, School of Business Administration, Rochester, Ml 48063.
TABLE 1

Firms in which Outside Suppliers Compete Against In-House Suppliers for the Firm's Business

$\begin{array}{ll}\text { Anhcuser-Busch } & \text { General Motors } \\ \text { Chryslet Motors } & \text { ITT Corporation } \\ \text { Ford Motor } & \text { Motorola, Inc. } \\ \text { FMC Corporation } & \text { PPG Industries } \\ \text { General Dynamics } & \text { Textron, Inc. } \\ \text { General Electric } & \text { Unisys Corporation }\end{array}$

of a prospective customer by its sales staff is one of the most critical. For the industrial salesperson this involves analyzing the prospect's requirements and needs [7] and identifying the buying center members and what and who influences their behavior [8], while being sensitive to the uniqueness that is generally associated with each buying organization [1]. This is typically a straightforward process. However, this activity changes rather dramatically when the competition includes an in-house supplier-a not uncommon situation.

The in-house supplier could be an affiliated company of the prospective customer, a subsidiary, another division, or simply an in-house plant that supplies parts and or components to the manufacturing group. Table I lists a number of Fortune 500 firms in which outside suppliers 
compete against in-house suppliers for the firm's business.

In certain situations involving outside suppliers the buyer-seller relationship has existed for so long that it takes on the characteristics of an in-house supplier relationship. Although this situation is confronted only occasionally today, the trend among original equipment manufacturers (OEMs) toward long-term contracts and the concomitant partnership is resulting in a closer, more trusting, information-sharing buyer-supplier relationship [3]. As a result, the industrial marketing organization will be facing an increasing number of competitive situations involving outside suppliers that will take on many, if not all, of the characteristics of an in-house supplier relationship.

Knowing how to compete against an in-house supplier is of importance because industrial sales personnel typically respond with one of two diametrically opposed actions: they act as if the situation were no different than competing against any other supplier, or they assume that they have no chance-and back off.

Neither approach is realistic. The fact that the current supplier is in-house will not impact the probability of the outside vendor's success. Rather, it is the nature of the relationship between the buying organization and the inhouse supplier that is of paramount importance in determining the likelihood of replacing an in-house supplier. The issue facing the salesperson therefore becomes: (1) what are the critical elements of this relationship; and (2) how can they be assessed with a minimum expenditure of time, energy, and cost?

In addressing these questions this article has two specific objectives. First, we present a decision-process model useful for ascertaining the sales opportunity when competing against an in-house supplier (Figure 1). The model provides a step-by-step method for deciding whether or not a potential vendor should try to scek the

JOHN W. HENKE, JR., Ph.D., is on the faculty of the School of Business Administration, Oakland University (Rochester, MI)

A. RICHARD KRACHENBERG, Ph.D., and THOMAS $F$. LYONS, Ph.D., are on the faculty of the School of Management, University of Michigan - Dearborn.

All three authors are also associated with Planning Perspectives, Inc. (Birmingham, MI.), a general management and marketing consulting firm. business of a buyer presently engaged in obtaining goods from an in-house supplier. Given the model, the second objective of the paper is to discuss some options open to the marketing organization as it moves through the model.

The model is based on discussions with numerous firms across several industries. These firms requested anonymity; thus, no company names are used, and product and specific industry situations are purposely left vague.

\section{EVALUATION METHODOLOGY}

In anticipation of using the model it is assumed that preliminary activities by the sales staff have determined that a basic level of compatibility exists between the marketing organization and the prospective customer. Since it is a well established fact that the number of individuals involved in the purchase decision, as well as their influence, varies with the circumstances $[2,4,5$, $6,9,10]$, a second assumption is that the appropriate number of people who may influence the decision will be contacted at each step of the model before moving on. Consequently, when we mention the buyer, we are referring to all individuals whose influence is sufficient to warrant contacting. Given these conditions and the awareness that the competitor is an in-house supplier, this model should be followed.

Figure 1 presents the model in a flowchart format. There are seven basic factors with which an outsider must be concerned when confronted by an in-house supplier situation. The first three are the primary determinants that influence the probability of replacing the in-house supplier. They are also the most difficult to evaluate because of their qualitative nature. The final four factors are more easily ascertained because of their quantitative characteristics. In any given situation, any one of the seven may be more or less important than the others, and any one can significantly reduce, if not completely stop, the chance for an outsider to obtain an order. The sequential array of the seven-item model presents a logical, orderly methodology for assessing this situation and qualifying the prospect.

\section{In-House Supplier Status}

The first and typically most important step is to determine the in-housc supplier's status. Status refers to the standing, in the buyer's mind, of the supplier's ability to 


\section{"A method for assessing the situation and qualifying the prospect".}

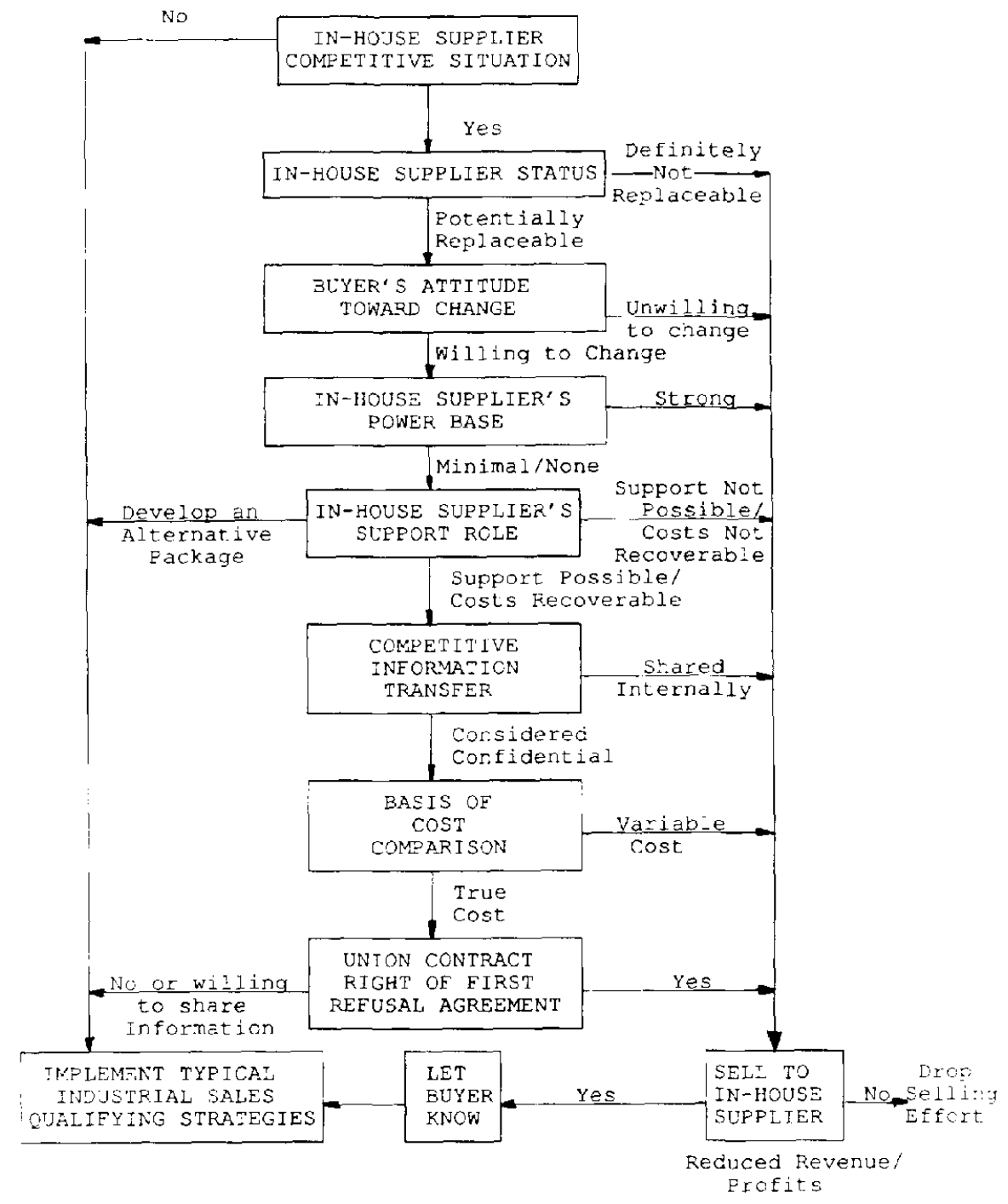

FIGURE 1. Decision Process to Determine the Feasibility of Selling to Firms with In-House Suppliers

meet real or perceived standards. The status may be the result of a formal evaluation process or may be subjective, having evolved over many years of a close relationship.

Many large firms, with increasing frequency, use a formal analysis process to rank their in-house suppliers relative to the current marketplace. Knowledge of this process, the specific evaluation criteria, and the resultant ranking can be very useful in determining the opportunity an outside supplier may have in replacing the in-house supplier. Even if no opportunity exists at the present time to replace the in-house supplier, an understanding of the process, its components, the concerns of the evaluators, 
etc., will provide significant insight into what the firm considers to be of paramount importance in meeting its needs.

The internal evaluation process typically involves a multi-level ranking system that is related to what is available in the marketplace. For example, one Fortune 50 company with whom we are acquainted assesses the parts, components, and subassemblies supplied by its inhouse suppliers on a three-rank scale. A green status ranking indicales that the in-house supplier is at least equal to the best available outside supplier and is anticipated to maintain that position in the near term. In this case buyers within the firm are told not to go to outside suppliers.

At the other extreme, the firm uses a red status ranking to indicate that the in-house supplier offering is so bad that the internal cross-divisional evaluating team believes it is in the best interests of the firm to purchase products from outside sources rather than obtain them from the inhouse supplier. The red status ranking indicates that the in-house supplying group is no longer an acceptable supplier of the item. This situation provides the outside supplier a window of opportunity to replace the in-house supplier. However, it must be realized that if the in-house supplier makes the necessary improvements to upgrade its status, the window will more than likcly be closed, with the in-house supplier eventually replacing the outside supplier.

Between the red and green status rankings is a yellow status, which indicates that the in-house supplier is somewhat competitive, but is not quite equivalent to what is available in the marketplace. However, given some time and some improvement, the supplier is anticipated to become as good or better than what is available in the open market, i.e., obtain a green ranking. A yellow status signals the buying groups within the firm that they must give the in-house supplier the opportunity to quote. However, the buyer can go to outside suppliers should conditions dictate.

We spoke with some buyers in the firm that utilizes this ranking system who felt that the yellow status gives them the right to seriously consider outside suppliers without strong regard for the in-house supplicr. On the other hand, other buyers in the same firm interpreted the yellow status as an indication that they should give their in-house supplier a more than fair opportunity to get its house in order. This difference of opinion suggests that the potential seller must not only determine the status of the in-house supplier, but must also find out the attitude of those individuals involved in the buying decision toward the status.

If no formal ranking process exists, then judicious inquiries to the appropriate personnel may provide some understanding of the status of the in-house supplier.

If the in-house supplier status is such that the buyer is unwilling or unable to replace the in-house supplier, the seller has two recourses: (1) drop the selling effort completely, or (2) try selling to the in-house supplier. On the other hand, if the status of the in-house supplier shows even moderate weakness, the seller should continue to evaluate the situation in light of the remaining factors in the model.

It must be recognized that timing is important in challenging the in-house supplier's position. Incremental improvements by outside suppliers can erode the favored status of the in-house supplier and a technological breakthrough can destroy it. Consequently, if the time is not right today, it may be at some point in the future.

\section{Buyer's Attitude Toward Change}

Whether the status is objective or subjective, the outside seller's opportunities for successfully usurping the in-house supplier's position begins with the buyer's willingness to consider replacing the in-house supplier. If the attitude of the buying group is not strongly predisposed toward the in-house supplier, or it has a pattern of going outside, in spite of favorable rankings, it would be worthwhile for the outside supplier to explore the buyer's attitude in more depth. It is particularly worthwhile if the in-house supplier has an uncertain status, for example, a yellow ranking.

The buyer's attitude toward change will give considerable insight into the approach and effort that should be taken to replace the in-house supplier. The attitude, of course, will be influenced by the frequency with which in-house suppliers have been replaced by outside suppliers in the past. One head purchasing agent of a multinational firm told us that his firm was definitely willing to have an outside supplier replace their in-house suppliers if the outside company could offer better quality, a more advanced technology, and/or lower costs. However, further questioning revealed that such a replacement had not occurred since 1971, because of the commitment to the in-house supplier.

In another situation where the anticipated marketing effort by the outside firm was considerable and the potential order quite significant, the president of the outside 


\section{how the in-house supplier will react to being replaced}

supplier telephoned the president of the in-house supplier firm, indicated their marketing intentions, and asked if they would be given a fair opportunity to obtain the business. This maneuver may seem bold, but the size of the potential order and the resources needed to wrest the business from the in-house supplier made the phone call a prudent move. Having given an affirmative reply to the caller, the president of the buying group was now committed to ensuring that the outsider would be treated fairly by the individuals involved in evaluating the competing proposals.

\section{In-House Supplier's Power Base}

It is also important to understand how the in-house supplier will react to the possibility of being replaced. Their reaction is dependent in large measure on their power base, which in turn will impact their capability to counteract potential replacement.

In some firms with which we are familiar, the in-house supplier's upper management has established a personal relationship with the upper management of the using group to the point that whenever a problem occurs which lower-level personnel cannot solve, executives from either side will call the other and quickly resolve the situation. Such a relationship goes beyond simply resolving problems. It is not unusual for upper management of the in-house supplier to call on their peers in the user group in a quasi-sales capacity to determine the level of "customer satisfaction."

When faced with potential replacement by an outside firm, the in-house supplier-buyer discussions may include the importance of maintaining the in-house business for the overall good of the company, stressing the fact that they are continuing to improve their products and that continued support would make good business sense. When such contact has failed to turn the buying group around, we are aware of instances where the in-house supplier management hierarchy has approached the corporate staff to convince them that it would be imprudent for the buying group to go with an outside supplier, because of the overall implications of the lost business to the company as a whole. Although this argument has not always stopped the outside supplier from getting the business, it can raise a formidable hurdle.

\section{In-House Supplier's Support Role}

Displacing an in-house supplier in today's competitive environment increasingly involves more than simply shipping the product to the buyer's manufacturing plants. The responsibilities of the in-house supplier could include a considerable array of support activities, at various levels within the buyer organization, which the new supplier would be expected to assume. For example, in many large corporations the in-house supplier provides a resident account representative at the buyer's facilities. In addition, various technical support personnel may work with the buyer's engineers, manufacturing plants, and/or distribution centers on a regular basis. Also, with some OEM products, aftermarket support may be critical, requiring regional inventories for rapid deployment of replacement parts. In addition, if top management of the in-house supplier plays an important role in the relationship that exists between the buyer and supplier, then top management of the outside supplier must be prepared to assume an equivalent role.

Alternatively, if it is discovered that the in-house supplier is not providing a level of support consistent with the marketplace, offering a higher level may be the most powerful competitive appeal that a potentially new supplier can make.

Obviously, there is a cost for any support that is expected to accompany the sale. These costs can have a significant impact on the outside supplier's willingness and ability to replace the in-house supplier. First, the seller should determine if it is capable of providing support at least equivalent to what the in-house supplier is furnishing. Second, by knowing the minimal level of support, the outside supplier will know how to structure the total package for the prospect. And, third, the true total costs can then be determined. 
The support needed to provide services, beyond simply supplying a product on time, should not be considered a deterrent to pursuing the business. The costs associated with testing, validating, design and engineering services, etc., can be a source of profit, not only a burden, depending upon the opportunity to pass on such costs and their accompanying profit margin.

However, if it appears that providing equivalent or better support is not feasible, the outside firm has three options. Once again it should consider selling directly to the in-house supplier. In this case, the support role would continue to be maintained by the in-house supplier. Secondly, it can develop an alternative product package or unique approach to the irreplaceable product-by doing such things as creating additional added value to the part by changing its configuration, or if it is a component, redirecting the buyer's sourcing approach by focusing on the ability to supply a critical part, regardless of its relative dollar value. Thirdly, it can drop the effort entirely.

\section{Competitive Information Transfer}

An in-house supplier often is considered by a buyer to be an integral part of the buyer's company. This advantage can include the sharing of information buyers have obtained from outside suppliers. Obviously, this information can help the in-house supplier neutralize any advantages an outside supplier might have.

Therefore, the outsider's primary concern when providing the buyer with information in an in-house supplier competitive situation is how the buyer will treat the information. The buyer might consider it to be confidential and, subsequently, will not share it with the in-house supplier. On the other hand, the buyer might pass on the information either to leverage the in-house supplier or because doing so is felt to be in the best interest of the firm.

When the buyer serves as a conduit of competitive information to the in-house supplier, the outside supplier is put at a decided disadvantage. An awareness of the possibility of such a situation occurring will alert the outside supplier to carefully control the level and type of information provided to the buyer.

The challenge is making a determination on how the individual buyer treats the information received. Obviously, the buyer's stance on this issue varies from individual to individual and from firm to firm. Two means can be utilized to determine their attitude. First, the buyer can be queried directly about the situation. They can be asked how they will treat the information, proprietary or not. Secondly, the buyer's attitude and behavior toward sharing information often can be ascertained by making inquiries either to employees of the firm with whom a trusting relationship has developed, or to other outside vendors who service the account. Finally, another direct method is to simply let the buyer know of the concern about the confidentiality of the information.

If the potential buyer treats the information as confidential, the selling effort can move forward without concern. However, if there is any doubt as to whether the information will be treated as confidential or not, a decision must be made as to the risk of the in-house supplier obtaining the information. If the availability of the information will negate any competitive advantage for the outsider, it may be worthwhile to forget about selling to the buying group and to consider selling direct to the inhouse supplier. If the information is considered too sensitive and/or selling to the in-house supplier is impractical, the final alternative is to drop the selling effort completely.

\section{Basis of Cost Comparison}

The buyer's method of comparing cost between competing product offerings may undercut the competitive advantage of the outside supplier. In some companies we studied, the goods provided by the in-house supplier are considered on a variable cost basis rather than on a full costs basis, i.e., the fixed costs of production capital equipment are regarded as sunk costs. As a result, if an outside supplier attempts to displace this in-house supplier, the buyer does not consider the fixed costs asso-

\section{The buyer's method of comparing cost/prices between competing offerings.}


ciated with the in-house supplier's equipment for comparative purposes. This results in the buyer comparing the variable cost of the current in-house supplied goods with the total cost (fixed plus variable costs) of the potential replacement product from the outside supplier. Obviously, this is a decided disadvantage for the outside supplier.

Although this specific example may seem an extreme case, it illustrates the importance of determining the basis of cost comparison utilized by the buyer. What would normally be immediately rejected as an unsound accounting practice may, in fact, be reality. Consequently, before expending significant resources in attempting to build a relationship with the buyer, it should be determined if the buyer uses accounting practices that will negate any price advantage, particularly if price is important in establishing a competitive advantage.

\section{Union Implications}

The model so far has focused on decision makers directly involved in evaluating the suppliers. There is another less obvious group of individuals within the buying firm that may influence the outcome of the outside supplier's selling effort-the union members in the in-house supplier's production plants.

In many large firms that are unionized, union contracts include provisions to stem the loss of work to outside suppliers. Although the wording varies among contracts, the union's local membership are given the right of first refusal to produce the goods for the costs quoted by a potential outside supplier. That is, if an outside supplier comes in with a lower price, the union members are given the opportunity to help the in-house supplier meet the price. The union can do this by increasing quotas per eight hour shift, changing the work rules, expanding classifications, etc. The contracts have a fixed period of time, typically 90 days, for the unions to respond.

If the qualifying assessment of the situation has reached this stage, the outside supplier is in a reasonably strong position to replace the in-house supplier. However, the greatest risk for the outside supplier can occur at this point because the buyer must fully disclose the outside supplier's price to the in-house supplier so the union local knows its cost goal. Even if the in-house supplier loses, the knowledge of how its outside competitors responded to the selling opportunity will be of value in future bidding.

In one situation an outside supplier displaced an in- house supplier with a lower cost and a better designed product that was easier to install at the OEM level and was easier to repair in the aftermarket. The outside supplier received a five-year contract, with the understanding that it had to continue to maintain this competitive advantage over the life of the contract. The need to give the union the opportunity to respond provided the inhouse supplier with an awareness of cost levels that it had to reach to regain the business. In addition, it gained a general understanding of how the outsider designed the product, although detailed knowledge of the outside supplicr's product was not directly made known to them. Under normal competitive conditions, the in-house supplier would have been hard-pressed to gain this level of knowledge before the appearance of the product in the marketplace. However, this knowledge enabled the inhouse supplier to leap-frog quickly and relatively easily to an even better product. The result was that the inhouse supplier replaced the outside supplier after only one year of sales even though a five year contract was initially agreed upon.

In another situation the outside supplier was awarded the contract only to have the buyer rescind it two months later because of union pressure. All start-up costs incurred by the outside supplier were paid; however, the cancellation was demoralizing. The order was in excess of $\$ 10$ million and created doubt as to the validity of other orders from the account. This incident, although it may be an isolated occurrence, is indicative of the effort unions will put into stopping out-sourcing in their plants.

Both of these incidents also suggest that the time for the outside supplier to celebrate the signing of a big new juicy contract is not while the ink is still wet on the purchase order. Celebration time comes, maybe, after two or three years into a five year contract, but not much before then.

\section{SOME FINAL STRATEGIC CONSIDERATIONS}

We have suggested more than once that if conditions are not favorable for selling directly to the buyer, consideration should be given to selling to the in-house supplier. Some firms fail to see this as a viable alternative. However, if you cannot fight them, it is not all bad to join them.

Selling to the in-house supplier represents an opportunity for sales that might not otherwise be available. This is particularly true when the in-house supplier func- 
tions as a systems integrator for the buying organization. The opportunities for revenue may be just as great. The downside risk, of course, is that this approach will result in the in-house supplier gaining complete product knowledge. Nevertheless, if there is no other possibility of selling to the firm, this may be the most feasible approach. If this approach is taken, the in-house buying group should be made aware of what is being done to help ensure that the in-house supplier does not stonewall the selling effort.

There are two additional technology-based situations, cach involving the in-house supplicr, that can provide potential sales opportunities for the outside supplier. If the outside supplier's products involve a technology that is more advanced than that of the in-house supplier, then clearly there is the possibility for sales. However, if this is the only competitive advantaged possessed by the outside seller, then it must be realized that sales under these conditions may be short-lived. As soon as the in-house supplier develops equivalent technology, the business will be brought in-house. On the other hand, the current products may involve the trailing edge of technology. The in-house supplier may therefore be in a high cost situation and desire to get out of the business. Under these circumstances the outside supplier may be eagerly accepted by the in-house supplier because they can then focus their efforts on more profitable products.

A final potential opportunity that might exist for the outside supplier involves a situation where over a period of time the in-house supplier's strategic direction has been changing. It still may be supplying the products, but they no longer fit into their strategic plan. These circumstances present an opportunity for the outside supplier to be a welcome replacement for the in-house firm. By maintaining an awareness of the in-house supplier's product activities, it often is possible to identify these opportunities.

For all of the above mentioned reasons the in-house supplier should not be totally disregarded. They may be competitors, but they can also be customers.

\section{SUMMARY}

Selling against an in-house supplier is not an easy task. Virtually all such sales situations are conducted on a playing field tilted to the advantage of the in-house supplier. The result is an uphill, but not impossible, struggle for outsiders. Consequently, it is extremely important for marketing organizations faced with this situation to take the time to qualify the buyer by cvaluating the in-house supplier-buyer relationship before either plunging into head-on competition with the in-house supplier or simply leaving the ficld.

The success of replacing the in-house supplier can be most effectively determined by utilizing the seven-step qualifying model, suggested in this article, which assesses:

1. In-House Supplier's Status,

2. Buyer's Attitude Toward Change,

3. In-house Supplier's Power Base,

4. In-House Supplier's Support Role,

5. Competitive Information Transfer,

6. Basis of Cost Comparison, and

7. Union Implication.

The insights gained from this assessment allow the user to determine whether to pursue the opportunity and, if so, under what strategic terms.

\section{REFERENCES}

1. Hutt, Michael D., and Speh, Thomas W., Industrial Marketing Management, 2nd Ed., The Dryden Press, New York 1985, p. 423.

2. Johnston, W. J., and Bonoma, T. V., The Buying Center: Structure and Interaction Patterns. Journal of Marketing 45. 143-156 (Summer I981).

3. Lyons, Thomas F., Krachenberg, A. Richard, and Henke, John W., Jr, Buyer-Supplier Relationships in the New Competitive Era (working paper), University of Michigan-Dearborn, Dearborn, MI (1989).

4. Morris, M. H., and Freedman, S. M., Coalitions in Organizational Buying, Industrial Marketing Management 13, 123-132 (1984).

5. Naumann, E., Lincoln, D. J., and McWilliams, R. D., The Purchase of Components: Functional Areas of Influence, Industrial Marketing Management 13, 113-122 (1984)

6. Patton, W. E., Puto, C. P., and King, R. H., Which Buying Decisions Are Made by Individuals and Not by Groups?, Industrial Marketing Management 15, 129-138 (1986)

7. Plank, Richard E., and Dempsey, William A., A Framework for Personal Selling to Organizations, Industrial Marketing Management 9, 143-149 (1980).

8. Reeder, Robert R., Brierty, Edward G., and Reeder, Betty H., Industrial Marketing: Analysis, Planning, and Control, Prentice-Hall, Englewood Cliffs, N.J., 1987, p. 368.

9. Silk, A. J., and Kalwani, M. U., Measuring Influence in Organizational Purchase Decisions, Journal of Marketing Rescarch 14, 165-181 (May 1982).

10. Thomas, R. J., Bases of Power on Organizational Buying Decisions, Industrial Marketing Management 13, 209-217 (1984). 